\title{
Factors associated with the exposure of vaccines to adverse temperature conditions: the case of North West region, Cameroon
}

\author{
Martin Ndinakie Yakum ${ }^{1,3^{*}}$, Jérôme Ateudjieu ${ }^{1,2,3}$, Fida Ramsina Pélagie ${ }^{4}$, Ebile Akoh Walter ${ }^{1,3}$ \\ and Pierre Watcho ${ }^{1}$
}

\begin{abstract}
Background: Adverse temperature recording in vaccine's cold chain is a major issue worldwide and this condition is known to compromise the quality of vaccines very rapidly. In Cameroon, with tropical climate, vaccines exposure to abnormal temperatures is very common. This study was conducted to identify factors associated to abnormal temperature recording in cold chain in the North West region.

Results: A total of 65 vaccinating health facilities were visited for the study from eight health districts. Concerning type of health facility, 48 (73.8\%) of the health facilities were governmental facilities. About 50 (76.0\%) of the facilities had a functional thermometer. Among the 50 health facilities with functional thermometer, abnormal temperatures were registered in 10 (20\%) health facilities during data collection and 12 (24\%) in the 2 months preceding collection. Factor significantly associated with abnormal temperature recording was the absence of an alternative power source $(\mathrm{OR}=6.5, \mathrm{p}=0.03)$.
\end{abstract}

Conclusion: The absence of an alternative source of power was significantly associated with abnormal temperature exposure in the 2 months preceding data collection. To improve on the quality of vaccines administered in North West region, each vaccinating health facility must have at least two sources of power supply.

Keywords: Vaccine, Cold chain, EPI, Immunization, Abnormal-temperature, Determinants, North-West, Cameroon

\section{Background}

Immunization is the most cost-effective preventive health intervention presently known in modern medicine $[1,2]$. To achieve full benefits of immunization, it is necessary to ensure high coverage, availability of potent vaccines, and timely delivery of scheduled immunizations [3, 4]. Vaccines are biological substances that gradually lose their potencies with time [5]. This loss of potency can be accelerated when exposed to excessive heat, freeze, or light $[5,6]$. The conservation of vaccine's potency from the manufacturer down to users is still very challenging. The exposure of vaccines to adverse temperature conditions does not only nullify the immunization effect, but

\footnotetext{
*Correspondence: martinyakum@yahoo.com

1 Department of Biomedical Sciences, University of Dschang,

P.O. Box 067, Dschang, Cameroon

Full list of author information is available at the end of the article
}

also induces adverse events following immunization [710]. Therefore, vaccines must be handled with care and a lot of attentions to ensure their quality and consequently full immunization benefit.

The role of cold chain is at the center of the Expanded Program on Immunization (EPI)'s activities since it maintains vaccines at a narrowed temperature environment (necessary for potency conservation) from the manufacturer down to the users $[1,2]$. However, within the cold chain, maintaining the temperature is never really easy due to varying environmental (weather, climate, and human activities) conditions [11]. Also, the equipment of the cold chain and power supply might register failure at any given time [2]. Consequently, continuous monitoring of the cold chain is indispensable so that vaccines exposure to adverse temperatures must be noticed early enough to take action. Cold chain failure and frequent 
exposure of vaccines to adverse temperature conditions have been documented in several parts of the world [11-15].

In developed countries, exposure to freezing temperatures is most frequent [15] conversely to developing countries where exposure to overheating is the most frequent $[12,13]$. It is believed that; tropical climates, unreliable power sources, and limited resources (material, financial, and human) are factors responsible for the frequent exposure of vaccine to overheating temperature conditions in developing countries $[1,2,5]$.

In Cameroon, outbreaks of vaccine preventable diseases are common and vaccine exposure to abnormal temperatures has been documented. The North West region is one of the regions constantly in epidemic of vaccine preventable diseases [16]. Also, high rate of exposure of vaccines to abnormal temperatures has equally been documented here [12]. This paper attempts to evaluate factors associated with vaccine exposure to adverse temperature condition at primary health care and district levels in the North West region of Cameroon.

\section{Methods Study design}

It was a cross sectional study targeting primary health care centers and district cold chains and was conducted in December 2013. Sampling was done at multiple levels and data collected with a preconceived and validated grid by observation and consultation of the vaccine-related documents. Associated factors were tested by calculating the odds ratio (OR), confidence interval and $P$ value with simple logistic regression and potential confounders controlled on a multiple logistic regression.

\section{Setting}

The North West Region of Cameroon had an estimated total population of 1,901,579 inhabitants for 2013 unevenly distributed among 19 health districts and 218 health areas. In total, there are 12 rural and 7 urban health districts. It lies between latitudes $5^{\circ} 40^{\prime}$ and $7^{\circ}$ to the North of the equator, and between longitudes $9^{\circ} 45$ and $11^{\circ} 10^{\prime}$ to the East of the Meridian. It is bordered to the south west by the South West region, to the south by West region, to the east by Adamawa region, and to the north by the Federal Republic of Nigeria. Concerning the weather temperatures during the 2 months targeted by this study (November and December 2013), the average temperature for the month of November was $19.4^{\circ} \mathrm{C}$ $\left(\min =14.9^{\circ} \mathrm{C}, \max =23.8^{\circ} \mathrm{C}\right)$ and that's of December was $19.5^{\circ} \mathrm{C}\left(\min =14.4^{\circ} \mathrm{C}, \max =24.6^{\circ} \mathrm{C}\right)$. Concerning power supply, about $80 \%$ of the region has access to electricity.

\section{Ethical statement and authorization}

The study targeted immunization's cold chain of health facilities and did not have anything to do with human subjects or their biological or personal information. Therefore, ethical approval was not requested. The authorization to carry out the research was obtained from the regional delegate of Public Health for the North West region.

\section{Study population}

The study involved vaccinating health facility in the selected health districts. Eight health districts were selected for the study. These included: Bamenda, Benakuma, Kumbo West, Ndop, Ndu, Nkambe, Tubah, and Wum Health Districts. Figure 1 shows the selected health district on the Map of the North West region, Cameroon

The Cameroon health system is divided into 3 levels: the central level, represented by the ministry of health; the intermediate level, represented by the regional delegations of public health; and the Peripheral level, represented by the health districts. The health district is managed by the district health service (DHS) which is headed by a district medical officer. A health district is made up of many health areas and each health area has at least one primary healthcare center which is responsible for delivering health care services to the population of the health area. The primary health care centers are categorized into: integrated health centers (IHC) headed by a senior nurse, Sub-divisional hospital headed by a medical doctor or district hospital which is headed by a medical director. Concerning cold chain management, this is ensured at the primary health care center by the head, but this function can be assigned to one of the personnel. The national guideline recommends that a temperature chart should be pasted on all vaccine refrigerators. The personnel responsible of cold chain monitoring reads and records vaccine temperature twice daily (morning and evening) on the chart. Also, all power interruptions are indicated on the chart. It should be noted that this chart is designed to collect information for 1 year. Consequently, the chart is replaced at the beginning of each year and the previous filled one archived in the health facility archiving system.

\section{Sampling}

All health districts of the North West were first of all grouped into 7 urban and 12 rural districts. Eight (42\%) of these health districts, that is, three urban and five rural districts were selected from their respective groups by simple random sampling technique. In each selected district, the list of all health facilities involved in the immunization activities was made and seven selected by systematic sampling technique. Also, the district's 


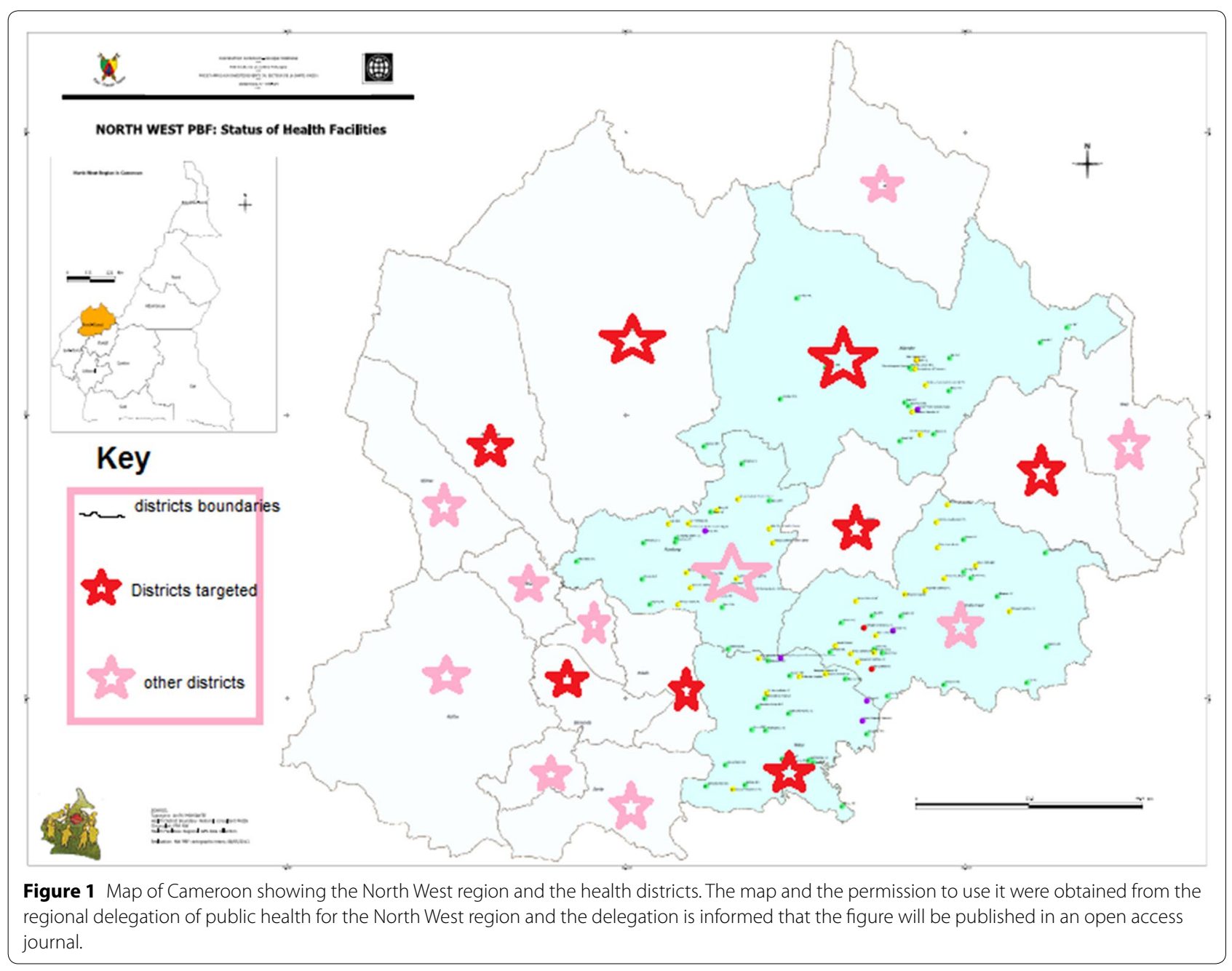

immunization cold chain system was evaluated. The sampling procedure was adopted to ensure the representative of the sample and to ensure the attainment of the sample size (estimated at 60) needed for the study.

\section{Data collection}

Data were collected with a preconceived and validated grid. Data collected were on the availability and functioning of vaccine refrigerator, present of cold chain contingency plan, presence of a source of power and an alternative source of power supply, presence of temperature recording sheet, presence of a functional thermometer in the vaccine fridge, presence of the national guidelines on immunization, the temperature at the moment of data collection. A cold chain contingency plan is a plan or procedure that will take effect if emergencies such as power interruption and refrigerator breakdown occur. It is also called emergency plan and the national guidelines recommends it to all vaccinating centers. In health facilities without a functional thermometer, data on temperature exposure could not be obtained but all other data were collected.

\section{Data analysis}

Data were analyzed with EpiInfo 3.5.4. In the first place, data forms were checked corrected and validated before entering into the computer. The entered data were further cleaned and analyzed. The availability and the functioning of cold chain materials were evaluated by calculating proportions such as the proportion of vaccine fridge having a functional thermometer, proportion of health facilities having a cold chain contingency plan. Also, the main outcome of interest was the abnormal temperature recorded during 2 months preceding data collection. Vaccines were said to have been exposed to adverse temperature conditions if one temperature recorded in the 2 months preceding data collection was greater than $+8^{\circ} \mathrm{C}$ or less than $+2^{\circ} \mathrm{C}$; else, the vaccines were said not exposed to adverse temperature conditions. Two months period was just the time chosen by the research team to evaluate the cold 
chain. The association of adverse temperature exposure with some potential factors was estimated by calculating the OR, CI, and the P value using a simple logistic regression. Potential confounder, number of refrigerator break down during the 2 months was controlled in a multiple logistic regression to obtain the adjusted OR. The confidence intervals were calculated at $95 \%$ confidence.

\section{Results}

\section{Characteristics of health facilities}

A total of 65 vaccinating health facilities were visited for the study from 8 Health Districts. Concerning type of health facility, 48 (73.8 [61.5-84.0] \%) of the health facilities were governmental facilities and 40 (61.5 [48.6-73.3] $\%$ were Integrated Health Centers (IHC). All district cold chains in the eight District Health Services (DHS) were evaluated.

\section{Availability and functioning of cold chain}

Table 1 below presents the availability and functioning of cold chain equipment and resources in the targeted health facilities.

\section{Temperature condition of vaccine}

Among the 50 health facilities that had a functioning thermometer in a vaccine fridge, 10 (20 [10.0-33.3] \%) of them had a thermometer reading out of the optimal vaccine storage temperature of $+2^{\circ} \mathrm{C}$ to $+8^{\circ} \mathrm{C}$ at the moment of data collection. Exposure to temperature higher than $8^{\circ} \mathrm{C}$ was more frequent $6(12 \%)$ than the exposure to temperature less than $2^{\circ} \mathrm{C} 4(8 \%)$. Furthermore, from the records of the 2 months preceding data collection, 12 (24.0 [13.1-38.2] \%) health facilities had recorded at least one temperature out of the optimal vaccine storage temperature of $+2^{\circ} \mathrm{C}$ to $+8^{\circ} \mathrm{C}$. Similarly, exposure to overheat was more frequent. A total of $12(24 \%)$ vaccine fridges were exposed to overheating (temperature higher than $8^{\circ} \mathrm{C}$ ) and $6(12 \%)$ exposed to cold (temperature lower than $+2^{\circ} \mathrm{C}$ ) in the two previous months to data collection. It is worth noting that all the vaccine refrigerators that were exposed to cold during the two months were equally exposed to overheating.

\section{Factors associated with the exposure of vaccines to adverse temperature conditions}

Table 2 presents the potential factor associated with the exposure of vaccine to abnormal temperature.

It should be noted that, none of the 10 health facilities that recorded abnormal temperature during the 2 months preceding data collection had a cold chain contingency plan whereas $12(30 \%)$ of those with correct temperature had a cold chain contingency plan.

\section{Discussion}

This paper attempts to identify factors associated with abnormal temperature recording in vaccine's cold chain.

Table 1 Availability and functioning of cold chain materials and equipment

\begin{tabular}{|c|c|c|c|c|}
\hline \multirow[t]{2}{*}{ Equipment and resources } & \multicolumn{4}{|c|}{ Frequency (\%) } \\
\hline & Total & DHS $(n=8)$ & $\mathrm{IHC}(\mathrm{n}=40)$ & Others $(n=17)$ \\
\hline \multicolumn{5}{|l|}{ Vaccine refrigerator $(n=65)$} \\
\hline Present & $57(87.7)$ & $8(100.0)$ & $36(90.0)$ & $13(76.5)$ \\
\hline Functioning & $53(81.5)$ & $8(100.0)$ & $32(80.0)$ & $13(76.5)$ \\
\hline \multicolumn{5}{|l|}{ Thermometer in functional refrigerators $(n=53)$} \\
\hline Present & $51(96.2)$ & $8(100.0)$ & $30(93.8)$ & 13(100.0) \\
\hline Functioning & $50(94.3)$ & $7(87.5)$ & $30(93.8)$ & $13(100.0)$ \\
\hline \multicolumn{5}{|l|}{ Temperature sheet on functional refrigerators $(n=53)$} \\
\hline Present & $50(94.3)$ & $6(75.0)$ & $31(96.9)$ & $13(100.0)$ \\
\hline Up-to-date & $25(47.2)$ & $3(37.5)$ & $16(50.0)$ & $6(46.2)$ \\
\hline Cold chain contingency plan present $(n=57)$ & $12(21.1)$ & $0(0.0)$ & $10(27.8)$ & $2(15.4)$ \\
\hline National immunization guidelines present $(n=65)$ & $41(63.1)$ & $5(62.5)$ & $28(70.0)$ & $8(47.1)$ \\
\hline One personnel assigned to monitor cold chain (65) & $50(76.9)$ & $8(100.0)$ & $28(70.0)$ & $14(82.4)$ \\
\hline \multicolumn{5}{|l|}{ Power sources $(n=65)$} \\
\hline Electricity & $53(81.5)$ & $8(100.0)$ & $30(75.0)$ & $15(88.2)$ \\
\hline Presence of at least two sources & $41(63.1)$ & $4(50.0)$ & $24(60.0)$ & $13(76.5)$ \\
\hline Cold boxes/vaccine carriers present & $65(100.0)$ & $8(100.0)$ & $40(100.0)$ & $17(100.0)$ \\
\hline Presence of icepack & $65(100.0)$ & $8(100.0)$ & $40(100.0)$ & $17(100.0)$ \\
\hline
\end{tabular}

Italic values indicate statistical significance $(p \leq 0.05)$. 
Table 2 Potential factor associated with the exposure of vaccine to abnormal temperature

\begin{tabular}{|c|c|c|c|c|c|c|c|}
\hline \multirow[t]{2}{*}{ Factor } & \multicolumn{4}{|c|}{ Simple logistic regression } & \multicolumn{3}{|c|}{ Multiple logistic regression } \\
\hline & OR & $\mathrm{Cl}$ & & $P$ value & OR $_{\text {adj }}$ & $\mathrm{Cl}$ & $P_{\text {value }}$ adj \\
\hline Absence of a cold chain contingency plan & 1.8 & & $0.33-9.59$ & 0.4990 & 1.5 & $0.28-8.53$ & 0.6220 \\
\hline Absence of guidelines & 1.0 & & $0.24-4.11$ & 0.6230 & 1.4 & $0.30-6.34$ & 0.6792 \\
\hline Absence of an alternative power source & 3.5 & & $0.83-14.69$ & 0.0843 & 6.5 & $1.14-37.05$ & $0.0352^{*}$ \\
\hline Was not supervised within 2 months & 1.6 & & $0.37-6.53$ & 0.4017 & 2.8 & $0.59-13.36$ & 0.1874 \\
\hline
\end{tabular}

* Statistically significant association.

It might save as a reference, helping to identify simple practices capable of improving the quality of vaccine.

It came out from the results that $24 \%$ of the vaccine refrigerators were exposed sub-optimal temperatures within a 2 months period. The problem of overheating was documented in all refrigerators that were exposed to sub-optimal temperatures whereas only $67 \%$ of them were exposed to freezing temperatures. The absence of an alternative source of power supply $(\mathrm{OR}=6.5, \mathrm{P}=0.03$ was associated with vaccine exposure to sub-optimal temperatures.

The exposure of vaccines to sub-optimal temperatures indicated in this paper is a worldwide problem and has been documented in many parts of the world [11-16]. This problem might be caused by factors related to the cold chain equipment, personnel, and/or power supplies $[17,18]$. The rate of exposure to sub-optimal temperatures may even be higher than the $24 \%$ documented here since exposure during transportation was not evaluated. For example, about $18.5 \%$ of health facility did not have a functional vaccine refrigerator and this implies they have to transport vaccines from and to the closest health facility with a functional cold chain before and after each immunization session respectively $[2,11]$. This increases the chance of exposing vaccines to heat or freezing, and consequently reduces vaccine's potency and increases the wastage rate $[3,11,12]$. Many research papers hold the opinion that freezing of vaccine is very common and more likely during transportation than overheating [3]. The paper proposes that the lack of an alternative source of power supply is associated with vaccines exposure to adverse temperature conditions. It was documented in a study in Nigeria that irregular power supply of health facilities and absence of standby generator were major risk factors of loss of vaccine potency [19]. Though not statistically significant here, the use of vaccine contingency plan is recommended by national and international guidelines on immunization [1-5] and supervision has showed to increase the adverse event following immunization detection and reporting rates in Cameroon [10]. Therefore, to minimize the rate of exposure of vaccine to adverse temperature conditions, all vaccinating centers should be provided with a vaccine refrigerator and an alternative power supply [20]. Also, these health facilities should be supervised regularly stressing on the use of contingency plan in all centers [21].

The need for innovative technology in cold chain monitoring that can help reduce the rate of vaccine exposure to adverse temperatures or that can lead to the production of thermo-stable vaccines has been well established [22-29]. Innovating technologies that can help target the weakness of cold chain identified in this paper include: production of thermo-stable vaccines [11, 30], computerization of cold chain monitoring, the use of electronic temperature monitor with alarm, and the production of long-life cold chain equipment [31]. A systematic review has documented the possibility to produce thermo-stable vaccines at low cost from plants [30]. The computerization and electronic cold chain monitoring and the production of long-life cold chain have equally been demonstrated [31]. However, the production of long-life cold chain can only prevent overheating but not freezing. The production of thermo-stable vaccines has been demonstrated only in some cases like the Influenza virus vaccine [30] and there is not yet enough evidence that it can also be done for other vaccines. Also, the computerization of cold chain monitoring and the use of electronic monitor with alarm have been tested and used in developed countries like the USA [31]. Therefore, all these innovating technologies to improve on cold chain still need to be tested in resourcelimited settings to enable their universal benefits.

The shortcomings of this paper include the fact that data were collected on vaccine only at storage and not during transportation; temperature records used were those registered twice daily which cannot actually tell how many times adverse temperatures occurred; and the fact that some health facilities refused participating in the study. However, Health districts and health facilities were selected randomly and the surveyors were well trained before the start of data collection. The results of this study can therefore be inferred to the whole of the North West region. 


\section{Conclusion}

Exposure of vaccines to adverse temperature conditions is a major problem in the North West region of Cameroon. This problem is not only grounded at health facilities but also at district health services which is supposed to oversee and supervise the immunization related activities of the health facilities. The lack of an alternative source of power supply was significantly associated with adverse temperature exposure of vaccines. In order to reduce the rate of vaccine exposure to adverse temperatures, we recommend the following practices to the regional delegation of Public Health for the North West region and the various district health services:

- Ensure that each vaccinating health facility and district health services is provided with at least one stand-by source of power different from the main source.

- Supervise the health facility regularly, not more than 2 month per facility and insisting on the use of contingency plan in all the facilities.

- Appoint one health personnel to monitor the cold chain in each health facilities and district health services.

\section{Abbreviations \\ DHS: District Health Service; EPI: expanded programme on immunization; HF: health facility; IHC: Integrated Health Center; OR: odds ratio; USA: United States of America.}

\section{Authors' contribution}

MNY and JA conceived the study, organized and coordinated collection of field data and guided the study design. MNY analyzed data, drafted the manuscript, and coordinated the review. FRP, EAW, and PW contributed in revising the manuscript. All authors read and approved the final manuscript.

\section{Author details \\ 1 Department of Biomedical Sciences, University of Dschang, P.O. Box 067, Dschang, Cameroon. ${ }^{2}$ Division of Health Operations Research, Ministry of Public Health, Yaoundé, Cameroon. ${ }^{3}$ Meilleur accès aux soins de santé (M.A.SANTE), P.O. Box 33490, Yaoundé, Cameroon. ${ }^{4}$ Bamenda health district service, Bamenda, Cameroon.}

\section{Acknowledgements}

We sincerely thank the Regional Delegation of Public Health for the North West and all the District heads for accepting and facilitating the data collection; Fon Kelvin Shomitang II for sponsoring the project; the Department of Biomedical Sciences of the University of Dschang and M.A.SANTE for technical supports.

\section{Compliance with ethical guidelines}

\section{Competing interest}

The authors declare that they have no competing interests.

Received: 24 March 2015 Accepted: 22 June 2015

Published online: 30 June 2015

\section{References}

1. Department of health: (2003) Cold chain And Immunization Operations manual. Guidelines for handling heat sensitive vaccines and pharmaceuticals. Department of Health, South Africa, pp 23-56

2. Ministry of Public Health (2009) Norms and standards for the expanded program on immunization of Cameroon. Ministry of Public Health, Cameroon, pp P37-P53

3. Wirkas T, Toikilik S, Miller N, Morgan C, Clements CJ (2007) A vaccine cold chain freezing study in PNG highlights technology needs for hot climate countries. Vaccine 2007(25):691-697

4. Luthi JC, Kessler W, Boelaert M (1997) A survey on vaccine efficacy in the city of Bongor (Chad) and its operational consequences for the vaccination program. Bull World Health Organ 75(5):427-433

5. World Health Organization (1998) Global Programme for Vaccines and Immunization: Expanded Programme on Immunization: safe vaccine handling: cold chain and immunizations. World Health Organization, Geneva, pp P8-P21

6. World Health Organization (2004) Immunization in practice: module 3: The cold chain. World Health Organization, Geneva, pp P1-P31

7. Silva ML, Luc Espírito-Santo AR, Martins MA, Silveira-Lemos D, PeruhypeMagalhães V, Caminha RC et al (2007) Activation/modulation of adaptive immunity emerges simultaneouslyafter 17DD yellow fever first-time vaccination: is this the key toprevent severe adverse reactions following immunization? Clin Exp Immunol 148:90-100

8. Thomas RE, Lorenzetti DL, Spragins W, Jackson D, Williamson T (2012) The safety of yellow fever vaccine 17D or 17DD in Children, pregnant women, HIV + individuals, and older persons: systematic review. Am J Trop Med Hyg 86(2):359-372

9. Cunha MPL, Dórea JG, Marques RC, Leão RS (2013) Vaccine adverse events reported during the first ten years(1998-2008) after Introduction in the State of Rondonia, Brazil. BioMed Res Int 2013:1-6

10. Ateudjieu J, Stoll B, Nguefack-Tsangue G, Tcangou C, Genton B (2014) Vaccine safety: effective of supervision or SMS on the reporting rate of adverse event following immunization(AEFI) with meningitis vaccine(MenAfriVacTM): a randomized controlled trial. Vaccine 32(43):5662-5668

11. Ateudjieu J, Kenfack B, Wakam B, Maurice D (2013) Program on immunization and cold chain monitoring: the status in eight health Districts in Cameroon. BioMed Central 21:596-600

12. Berhane $Y$, Demissie M (2000) Cold chain status at immunization centres in Ethiopia. East African Med J 77(9):P476-P479

13. Matthias D, Robertson J, Michelle M, Sophie N, Carib N (2007) Freezing temperatures in the vaccine cold chain. Elsevier 25:3980-3986

14. Yogindra S, Hemant L, David P, Lester B, Gajendra S, Ben S (2007) Evaluation of the Cold-Chain for Oral Polio Vaccine in a Rural District of India. Int Obs Public Health Rep 122:112-121

15. Simba DO, Msamanga Gl (1994) Use of cold chain to assess vaccine exposure to adverse temperatures in rural Tanzania. East African Medical Journal, Tanzania

16. Félicitée $\mathrm{N}$, Mathurin $\mathrm{T}$, Andreas $\mathrm{C}$, Roger $\mathrm{D}$, Innocent $\mathrm{K}$, Tetanye E et al (2011) Morbidity and mortality from measles in Cameroonian children: implications for measles control. Open Area Stud J 4:7-13

17. Saffar H, Saffar MJ, Saffar H (2013) Vaccination in developing countries: a review of probable factors for lower responses to vaccine. J Pediatr Rev $1(1): 12-18$

18. Adu FD, Adedeji AA, Esan JS, Odusanya OG (1996) Live viral vaccine potency: an index for assessing the cold chain system. Public Health 110(6):325-330

19. Azira B, Norhayati MN, Norwati D (2014) Optimal temperature of cold chain and its associated factors among general practitioners in Kelantan, Malaysia. Int J Collab Res Intern Med Public Health 6(6):168-179

20. Jegede AS, Owumi BE (2013) Factors influencing infant immunization uptake in the yoruba community of southwestern Nigeria. J Community Med Health Educ. 3:215. doi:10.4172/2161-0711.1000215

21. Sorungbe AOO (1989) Expanded programme on immunisation in Nigeria. Rev Infect Dis 11:S509-S511 
22. Murhekar MV, Dutta S, Kapoor AN, Bitragunta S, Dodum R, Ghosh P et al (2013) Frequent exposure to suboptimal temperatures in vaccine coldchain system in India: results of temperature monitoring in 10 states. Bull World Health Organ 91:906-913

23. Turner N, Athene L, Roberts R (2011) Assessing the effectiveness of cold chain management for childhood vaccines. J Prim Health Care 3:279-282

24. Shrivastava A, Gupta N, Upadhyay P, Puliyel J (2012) Caution needed in using oral polio vaccine beyond the cold chain: Vaccine vial monitors may be unreliable at high temperatures. Indian J Med Res 135:520-522 (St Stephens Hospital, Delhi \& *National Institute of Immunology, New Delhi, India)

25. Nkowane BM, Bart SW, Orenstein WA, Baltier M (1987) Measles outbreak in a vaccinated school population: epidemiology, chains of transmission and the role of vaccine failures. Am J Publ Health 77:434-438

26. Simba DO, Msamanga Gl (1994) Use of cold chain to assess vaccine exposure to adverse temperatures in rural Tanzania. East Afr Med J 71:445-446
27. Nelson CM, Wibisono H, Purwanto H, Mansyur I, Moniaga V, Widjaya A (2004) Hepatitis B vaccine freezing in the Indonesian cold chain: evidence and solutions. Bull World Health Organ 82:99-105

28. Henjeet K, Lye MS, Sinniah M, Schnur A (1996) Evaluation of cold chain monitoring in Kelantan, Malaysia. Bull World Health Organ 74:391-397

29. Yakum MN, Ateudjieu J, Walter EA, Watcho P (2015) Vaccine storage and cold chain monitoring in the North West region of Cameroon: a cross sectional study. BMC Res Notes 8(145):1-7

30. Penney Claire A, Thomas David R, Deen SS, Walmsley AM (2011) Plantmade vaccines in support of the Millennium Development Goals. Review. Plant Cell Rep 30:789-798. doi:10.1007/s00299-010-0995-5

31. Center for disease control and prevention (2021) Storage \& Handling TOOLKIT: national center for immunization and respiratory diseases. http://www.cdc.gov/.../storage/.../storage-handling-toolkit
Submit your next manuscript to BioMed Central and take full advantage of:

- Convenient online submission

- Thorough peer review

- No space constraints or color figure charges

- Immediate publication on acceptance

- Inclusion in PubMed, CAS, Scopus and Google Scholar

- Research which is freely available for redistribution

Submit your manuscript at www.biomedcentral.com/submit
() Biomed Central 